\title{
Relationship between the Susceptibility of Various Bacteria to Active Oxygen Species and to Intracellular Killing by Macrophages
}

\author{
By YOSHITAKA YAMADA, 1.2* HAJIME SAITO, 2 HARUAKI TOMIOKA? \\ AND JOJI JIDOI \\ Department of Dermatology ${ }^{1}$ and Department of Microbiology and Immunology'. \\ Shimane Medical University, Izumo 693, Japan
}

(Received 30 September 1986; revised 18 February 1987)

\begin{abstract}
The susceptibilities of six micro-organisms to active oxygen species generated in the xanthine oxidase-mediated bactericidal system were as follows: Escherichia coli $81 \geqslant$ Listeria monocytogenes EGD $\geqslant$ Salmonella typhimurium HK B-1 $\geqslant$ Staphylococcus aureus Smith $\gg$ Micohacterium tuberculosis $\mathrm{H}_{37} \mathrm{Rv} \simeq$ Candida albicans $\mathrm{NIH} \mathrm{A207}$ (the last two organisms were essentially resistant to this system). The $\mathrm{H}_{2} \mathrm{O}_{2}-\mathrm{Fe}$-mediated halogenation system exhibited a higher microbicidal activity. When the micro-organisms were compared for their sensitivity to bactericidal activity of resident mouse peritoneal macrophages $(\mathrm{M} \phi \mathrm{s})$, C. albicans, Staph. aureus and $E$. coli were killed rapidly, whereas $M$. tuberculosis, L. monocytogenes and S. typhimurium were more resistant. In tests for the ability to trigger an oxidative burst in mouse peritoneal $\mathrm{M} \phi \mathrm{s}$ (as measured by chemiluminescence), Staph. aureus showed the highest activity followed by the other organisms in the following order: $C$. albicans $>E$. coli $>L$. monocytogenes $\simeq M$. tuberculosis. S. typhimurium exhibited no triggering activity. The high susceptibility of Staph. aureus and $E$. coli to $\mathrm{M} \phi$ bactericidal activity, and the partial resistance of L. monocytogenes and $M$. tuberculosis, correlated with their susceptibility to active oxygen and the $\mathrm{H}_{2} \mathrm{O}_{2}-$ Fe-mediated halogenation reaction.
\end{abstract}

\section{INTRODUCTION}

In the foregoing paper (Yamada et al., 1987), we reported that $\mathrm{O}_{2}^{-}$and $\mathrm{OH}$ play important roles in the expression of antimicrobial activity by the xanthine oxidase -acetaldehyde (XOA) Fe-EDTA system, which enzymically generates active oxygen species. This antimicrobial system readily killed Staphylococcus aureus, Escherichia coli, Listeria monocytogenes and Salmonella typhimurium, but Candida albicans and Mycobacterium tuberculosis were highly resistant to it. Antimicrobial activity of active oxygen species can be demonstrated directly, but also by $\mathrm{H}_{2} \mathrm{O}_{2}$-mediated halogenation reactions such as the myeloperoxidase $-\mathrm{H}_{2} \mathrm{O}_{2}$-halidemediated bactericidal system in polymorphonuclear leucocytes (PMNs) (Klebanoff, 1968, 1974; Klebanoff \& Shepard, 1984; Locksley et al., 1982). Although macrophages (M $\phi$ s) have no myeloperoxidase (Klebanoff, 1980), iron at physiological concentrations (Flitter et al., 1983; Gutteridge et al., 1981; Halliwell \& Gutteridge, 1984) or endogenous catalase can catalyse the halogenation system (Gee et al., 1970; Klebanoff, 1969, 1982a; Klebanoff \& Hamon, 1975; Levitz \& Diamond, 1984). At the acid pH achieved within the phagolysosome, the ironmediated halogenation system acts more efficiently and has a more potent antimicrobial activity than at neutral and alkaline pH (Klebanoff, 1982a; Levitz \& Diamond, 1984). Therefore, $\mathrm{H}_{2} \mathrm{O}_{2}-\mathrm{Fe}$-mediated halogenation is thought to be important in the microbicidal mechanism of $\mathrm{M} \phi \mathrm{s}$. In this study, we examined the susceptibility of various organisms to the $\mathrm{H}_{2} \mathrm{O}_{2}-\mathrm{Fe}-$ mediated halogenation system and to the antimicrobial action of mouse peritoneal $\overline{\mathrm{M}} \phi \mathrm{s}$.

\footnotetext{
Abbretiations: i.p., intraperitoneal(ly); $\mathrm{M} \phi$, macrophage: PEC, peritoneal exudate cells; PMA, phorbol myristate acetate: PMN, polymorphonuclear leucocyte; XOA, xanthine oxidase-acetaldehyde.
} 


\section{METHODS}

Animals. Four-week-old female ddY mice were purchased from the Shizuoka Laboratory Animal Center, Shizuoka, Japan. At the time of experiment, they were 6 to 8 weeks old.

Organisms. The test organisms and their sources were as follows: Escherichia coli 81 and Staphylococcus aureus Smith (A. Matsumae, Kitasato Institute, Tokyo, Japan), Listeria monocytogenes EGD (K. Takeya, Kyushu University, Fukuoka, Japan), Salmonella typhimurium HKB-1 and Candida albicans NIH A207 (M. Kuwabara, Hiroshima Prefectural Hospital, Hiroshima, Japan), bacillus Calmette-Guérin (BCG) (Japan BCG Laboratory, Tokyo). Organisms were cultured as described previously (Yamada et al., 1987).

Chemicals. All reagents were purchased from Wako Pure Chemical.

Microbicidal activity of $\mathrm{H}_{2} \mathrm{O}_{2}-\mathrm{Fe}$-iodide system. Microbicidal activity of the $\mathrm{H}_{2} \mathrm{O}_{2}-\mathrm{Fe}$-iodide system $\left(\mathrm{H}_{2} \mathrm{O}_{2}-\right.$ $\mathrm{Fe}$-mediated halogenation system) was measured according to the method of Klebanoff (1982a). The reaction mixture $(2 \mathrm{ml})$, consisting of 10 or $100 \mu \mathrm{M}$-sodium iodide and $\mathrm{H}_{2} \mathrm{O}_{2}$, various concentrations of ferrous sulphate,

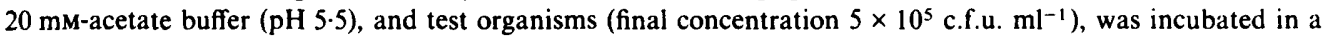
shaking water bath at $37{ }^{\circ} \mathrm{C}$ for $60 \mathrm{~min}$. The number of c.f.u. of the resultant microbial suspension was then determined on appropriate agar media after serial 10-fold dilutions with $0.15 \mathrm{M}$-saline (Yamada et al., 1987).

Microbicidal activity of host peritoneal $M \phi s$. Mice were given intraperitoneally (i.p.) viable ( $0.01 \mathrm{mg}$ per mouse) and heat-killed ( $0.1 \mathrm{mg}$ per mouse) BCG $21 \mathrm{~d}$ and $3 \mathrm{~d}$ before microbial challenge, respectively. Normal and BCGtreated mice were infected i.p. with $1 \times 10^{6}$ test organisms suspended in saline. Two hours later, micro-organisms present in the peritoneal cavity were harvested in Hanks' balanced salt solution (HBSS) and sonicated for $20 \mathrm{~s}$ with a Handy Sonic model UR-20P (Tomy Seiko Co., power 10) to free and disperse the phagocytosed microorganisms, and the number of c.f.u. was determined. To determine the virulence of test organisms, mice were injected i.p. with $1 \times 10^{6}$ organisms per mouse and survival of the infected animals was observed for up to 4 weeks.

Measurement of $M \phi$ oxidative burst. This was done by a chemiluminescence method. Mouse peritoneal exudate cells (PEC) were harvested with HBSS $4 \mathrm{~d}$ after i.p. injection of $1 \mathrm{mg}$ zymosan A per mouse. The PEC contained more than $85 \%$ of $\mathrm{M} \phi \mathrm{s}$, with $9 \%$ contamination by PMNs. The incubation mixture $(1 \mathrm{ml})$, consisting of PEC $\left(10^{6}\right.$ cells in $0.9 \mathrm{ml}$ ) and $0.1 \mathrm{ml} 0.1 \mathrm{~mm}$-luminol, was measured for background chemiluminescence at $37^{\circ} \mathrm{C}$ in a Toyo Kagaku lumicounter ATP-958. After addition of various concentrations of microbial suspension $(0 \cdot 1 \mathrm{ml})$, light emissions were counted for $10 \mathrm{~s}$ at $2 \mathrm{~min}$ intervals for up to $10 \mathrm{~min}$. After the incubation, PEC were smeared on a glass slide, stained with Giemsa stain and the number of $M \phi$-associated organisms was counted microscopically.

\section{RESULTS}

Susceptibility of various micro-organisms to the $\mathrm{H}_{2} \mathrm{O}_{2}-\mathrm{Fe}$-mediated halogenation system

Table 1 shows the susceptibility of the test organisms to microbicidal activity of $\mathrm{H}_{2} \mathrm{O}_{2}-\mathrm{Fe}-$ iodide-mediated halogenation system. In the presence of $10 \mu \mathrm{M}$ each of $\mathrm{H}_{2} \mathrm{O}_{2}$ and iodide but in the absence of $\mathrm{Fe}^{2+}$, considerable killing of $L$. monocytogenes was noted, whereas the other organisms were not killed. Addition of $10 \mu \mathrm{M}-\mathrm{Fe}^{2+}$ markedly augmented the microbicidal activity of this system, and killing of the test organisms was observed in the following order: Staph. aureus $\simeq E$. coli $\simeq S$. typhimurium $>$ L. monocytogenes $>M$. tuberculosis. Although $C$. albicans was most resistant to this system, reductions of two orders of magnitude in the numbers of c.f.u. of the organisms was observed in the presence of equimolar amounts of $\mathrm{Fe}^{2+}$ and iodide. In the presence of $100 \mu \mathrm{M}$ each of $\mathrm{H}_{2} \mathrm{O}_{2}$ and iodide, rapid killing of Staph. aureus, E. coli, S. typhimurium and $L$. monocytogenes was noted, even in the absence of $\mathrm{Fe}^{2+}$. In contrast, $M$. tuberculosis and C. albicans were killed in the halogenation system with $100 \mu \mathrm{M}$ each of $\mathrm{H}_{2} \mathrm{O}_{2}$ and iodide only when $\mathrm{Fe}^{2+}$ was added at concentrations over $10 \mu \mathrm{M}$. In summary, the sensitivity of test micro-organisms to the $\mathrm{H}_{2} \mathrm{O}_{2}-\mathrm{Fe}$-mediated halogenation system was in the order $S$. typhimurium $\simeq E$. coli $\simeq$ Staph. aureus $>$ L. monocytogenes $>M$. tuberculosis $>C$. albicans.

\section{Susceptibility of various organisms to the microbicidal activity of $M \phi s$}

Table 2 shows the susceptibility of test organisms to mouse peritoneal $\mathbf{M} \phi$-mediated killing in vivo. As indicated in experiment 1,C.albicans, Staph. aureus and E. coli were readily eliminated from the peritoneal cavity of the normal mice during the first 2 h after i.p. injection, whereas $S$. typhimurium, L. monocytogenes and $M$. tuberculosis were less readily killed. Since resident $\mathrm{M} \phi \mathrm{s}$ were dominant in the PEC populations of the normal mice [nearly $60 \%$ of the PEC were M $\phi \mathrm{s}$ with a very low capacity to produce $\mathrm{O}_{2}^{-}$and $\mathrm{H}_{2} \mathrm{O}_{2}$ in response to phorbol myristate acetate (PMA)], and PMN contamination was low, the elimination of C. albicans, Staph. aureus and E. 
Table 1. Microbicidal effect of the $\mathrm{H}_{2} \mathrm{O}_{2}$-iodide-Fe-mediated halogenation system ( $\mathrm{pH} 5 \cdot 5$ )

The results are means of two determinations \pm the range. A value of 0 indicates that no survivors were detected. The initial values of $\log$ c.f.u. were as follows: Staph. aureus, $5 \cdot 80 \pm 0 \cdot 02 ; E$. coli, $5 \cdot 74 \pm 0$; L. monocytogenes, $5.88 \pm 0 ; S$. typhimurium, $5.88 \pm 0.01 ; M$. tuberculosis, $5.39 \pm 0.01 ; C$. albicans, $5 \cdot 85 \pm 0 \cdot 02$.

\begin{tabular}{|c|c|c|c|c|c|c|c|c|}
\hline \multirow{2}{*}{\multicolumn{3}{|c|}{ Addition $(\mu \mathrm{M})$}} & \multicolumn{6}{|c|}{ Survival (log c.f.u.) } \\
\hline & & & \multirow{2}{*}{$\begin{array}{l}\text { Staph. } \\
\text { aureus }\end{array}$} & \multirow[b]{2}{*}{ E. coli } & \multirow{2}{*}{$\begin{array}{l}\text { L. monocyto- } \\
\text { genes }\end{array}$} & \multirow{2}{*}{$\begin{array}{l}\text { S. typhi- } \\
\text { murium }\end{array}$} & \multirow{2}{*}{$\begin{array}{l}\text { M. tuber- } \\
\text { culosis }\end{array}$} & \multirow[b]{2}{*}{ C. albican } \\
\hline $\mathrm{H}_{2} \mathrm{O}_{2}$ & Iodide & $\mathrm{Fe}^{2+}$ & & & & & & \\
\hline 0 & 0 & 0 & $5.66 \pm 0.01$ & $5.68 \pm 0.02$ & $5.89 \pm 0.01$ & $5.90 \pm 0.01$ & $5.53 \pm 0.02$ & $5.85 \pm 0.03$ \\
\hline 10 & 0 & 0 & $5.74 \pm 0.02$ & $5.72 \pm 0.02$ & $5.88 \pm 0.02$ & $5.69 \pm 0.04$ & $5.34 \pm 0.08$ & $5 \cdot 85 \pm 0$ \\
\hline 0 & 10 & 0 & $5.29 \pm 0.03$ & $5.73 \pm 0.01$ & $5.84 \pm 0.03$ & $5.86 \pm 0.03$ & $5.26 \pm 0.06$ & $5.82 \pm 0.03$ \\
\hline 10 & 10 & 0 & $5.48 \pm 0.02$ & $5.54 \pm 0.09$ & $3.42 \pm 0.24$ & $5 \cdot 34 \pm 0.30$ & $5.49 \pm 0.09$ & $5.89 \pm 0.01$ \\
\hline 10 & 10 & 1 & $\overline{0}$ & $\overline{0}$ & $2.40 \pm 0.02$ & $\overline{0}$ & $2.81 \pm 0.14$ & $5.85 \pm 0.02$ \\
\hline 10 & 10 & 10 & 0 & 0 & $\overline{0}$ & 0 & $\overline{0}$ & $3.82 \pm 0.18$ \\
\hline 10 & 10 & 100 & 0 & 0 & $0.55 \pm 0.21$ & 0 & $3.63 \pm 0.07$ & $4.67 \pm 0.09$ \\
\hline 100 & 0 & 0 & $5.74 \pm 0.18$ & $5.71 \pm 0.01$ & $5.85 \pm 0.06$ & $5.74 \pm 0.01$ & $5.28 \pm 0.08$ & $5.82 \pm 0.01$ \\
\hline 0 & 100 & 0 & $5.51 \pm 0.31$ & $5.69 \pm 0.02$ & $5.88 \pm 0.03$ & $5.87 \pm 0.02$ & $5.55 \pm 0.03$ & $5.78 \pm 0.02$ \\
\hline 100 & 100 & 0 & $\overline{0}$ & $\overline{0}$ & $2.02 \pm 0.17$ & $\overline{0}$ & $4.52 \pm 0.11$ & $5.81 \pm 0.06$ \\
\hline 100 & 100 & 1 & 0 & 0 & $\overline{0}$ & 0 & $0.43 \pm 0.09$ & $5.36 \pm 0.08$ \\
\hline 100 & 100 & 10 & 0 & 0 & 0 & 0 & $\overline{0}$ & $\overline{0}$ \\
\hline 100 & 100 & 100 & 0 & 0 & 0 & 0 & 0 & 0 \\
\hline
\end{tabular}

Table 2. Susceptibility of the test organisms to microbicidal activity of $M \phi$

Mice were given i.p. $1 \times 10^{6}$ each of the indicated organisms, and the number of viable organisms in the peritoneal cavity was measured $2 \mathrm{~h}$ later. The number of organisms at $0 \mathrm{~h}$ is fixed at $100 \%$. The results are means \pm standard error $(n=3)$.

\begin{tabular}{|c|c|c|c|c|c|c|}
\hline & \multicolumn{6}{|c|}{ Survival (\%) } \\
\hline & $\begin{array}{l}\text { Staph. } \\
\text { aureus }\end{array}$ & E. coli & $\begin{array}{l}\text { L. monocyto- } \\
\text { genes }\end{array}$ & $\begin{array}{l}\text { S. typhi- } \\
\text { murium }\end{array}$ & $\begin{array}{l}\text { M. tuber- } \\
\text { culosis }\end{array}$ & C. albicans \\
\hline $\begin{array}{l}\text { Expt 1: normal mice } \\
\text { (resident } \mathrm{M} \phi \text { ) }\end{array}$ & $9 \cdot 3 \pm 0 \cdot 2$ & $10 \cdot 5 \pm 0 \cdot 9$ & $81 \cdot 3 \pm 23 \cdot 3$ & $55 \cdot 0 \pm 5 \cdot 2$ & $93 \cdot 7 \pm 6 \cdot 0$ & $4 \cdot 2 \pm 0 \cdot 1$ \\
\hline $\begin{array}{l}\text { Expt 2: BCG-treated mice } \\
\text { (activated } \mathbf{M} \phi)^{*}\end{array}$ & $8 \cdot 6 \pm 1 \cdot 0$ & $1 \cdot 5 \pm 0 \cdot 3$ & $2 \cdot 8 \pm 1 \cdot 4$ & $72 \cdot 1 \pm 34 \cdot 9$ & $28 \cdot 0 \pm 3 \cdot 5$ & $0 \cdot 3 \pm 0 \cdot 1$ \\
\hline
\end{tabular}

* Mice were injected i.p. with 0.01 and $0.1 \mathrm{mg}$ viable and heat-killed $\mathrm{BCG}$ per mouse 21 and $3 \mathrm{~d}$ before bacterial challenge, respectively.

coli from the peritoneal cavity is thought to be attributable to resident $\mathrm{M} \phi \mathrm{s}$. Experiment 1 (Table 2) shows that the susceptibility of the test organisms to the microbicidal action of resident $\mathrm{M} \phi \mathrm{s}$ is in the following order: $C$. albicans $\simeq S t a p h$. aureus $\simeq E$. coli $>S$. typhimurium $\geqslant L$. monocytogenes $\simeq M$. tuberculosis. In experiment 2 (Table 2 ), the resident $\mathbf{M} \phi \mathbf{s}$ in the peritoneal cavity were immunologically activated by double injections of viable and heat-killed BCG at $21 \mathrm{~d}$ and $3 \mathrm{~d}$ before microbial challenge, respectively [in this case, the PEC were mainly composed of $\mathbf{M} \phi \mathbf{s}(75 \%)$ and other cells such as lymphocytes; the resultant $\mathbf{M} \phi$ s showed a high PMA response, releasing $430 \mathrm{nM}-\mathrm{H}_{2} \mathrm{O}_{2}$ in response to $10 \mathrm{ng}$ PMA ml ${ }^{-1}$ per $10^{6}$ cells; unpublished data]. In this case, $C$. albicans, $\bar{E}$. coli and $L$. monocytogenes were readily eliminated from the peritoneal cavity. Although $M$. tuberculosis was also more rapidly killed by activated $\mathrm{M} \phi \mathrm{s}$ than by resident $\mathrm{M} \phi \mathrm{s}$, the organisms was still relatively resistant. On the other hand, $S$. typhimurium was highly resistant to both the resident and the activated $M \phi s$. The high resistance of $S$. typhimurium $\mathrm{HKB}-1$ to the microbicidal activity of host $\mathrm{M} \phi \mathrm{s}$ was consistent with its high virulence in mice : $1 \times 10^{6}$ organisms given i.p. to mice killed $90 \%$ of the host animals within 1 week, while the same number of the other micro-organisms killed only $20 \%$ or less of mice within 4 weeks. 


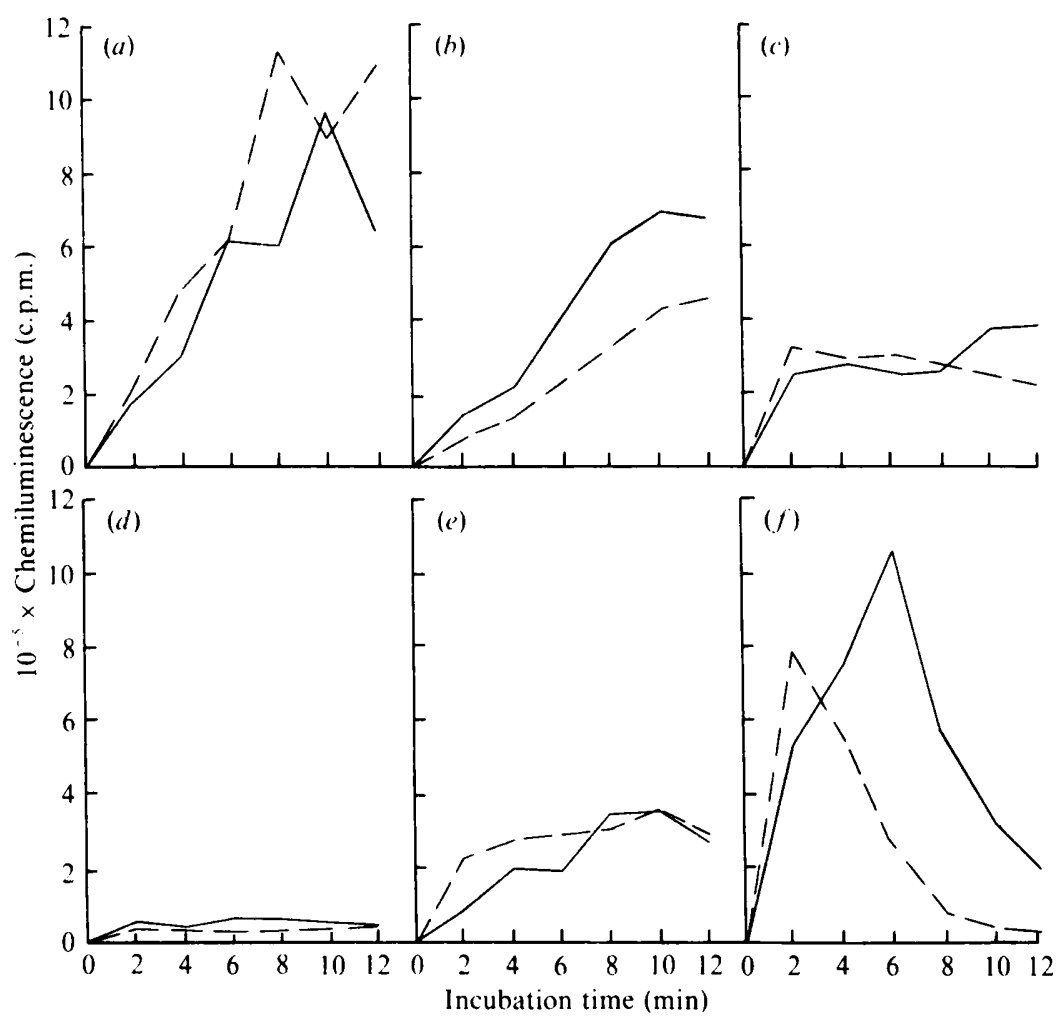

Fig. 1. Chemiluminescence-triggering ability of Staph. aureus (a), E. coli (b), L. monocvtogenes (c), $S$. typhimurium $(d), M$. tuberculosis $(e)$ and $C$. albicans $(f)$. Reaction mixture $(1 \mathrm{ml})$, consisting of $1 \times 10^{6}$ zymosan $\mathrm{A}$-induced $\mathrm{M} \phi \mathrm{s} \mathrm{ml}^{-1} .0 .1 \mathrm{~mm}$-luminol and various concentrations of microbial suspension (m.o.i. 40, solid line: m.o.i. 20, broken line), was measured for chemiluminescence at $37^{\circ} \mathrm{C}$.

Bacterial activation of the $M \phi$ oxidative burst

Fig. 1 shows chemiluminescence of zymosan A-induced $\mathbf{M} \phi$ s in contact with test organisms at m.o.i. values of 20 and 40. The test organisms were examined for their ability to trigger an oxidative burst by zymosan A-induced mouse PEC (composed of $88 \% \mathrm{M} \phi$ s, with low PMN contamination). Over the first $10 \mathrm{~min}$, Staph. aureus triggered the highest chemiluminescence, followed by the other micro-organisms in the following order; Staph. aureus $\geqslant C$. albicans $>E$. coli $>L$. monocytogenes $\simeq M$. tuberculosis. $S$. typhimurium failed to trigger chemiluminescence (Fig. 1d). Three groups of test organisms could be recognized, according to the light emission patterns of $\mathrm{M} \phi \mathrm{s}$ induced by contact with organisms: (1) chemiluminescence continued to increase during the course of measurement for up to $12 \mathrm{~min}$ (Staph. aureus and E. coli): (2) chemiluminescence reached a maximum in the early phase and declined thereafter (C.albicans); (3) chemiluminescence reached a plateau in the early phase ( $L$. monocytogenes, $M$. tuberculosis and $S$. typhimurium). Patterns (2) and (3) suggest the release from the test organisms of inhibitory factors against $\mathrm{M} \phi$ chemiluminescence.

$S$. typhimurium, which lacked $\mathbf{M} \phi$-chemiluminescence-triggering activity, was associated with $M \phi$ cells to the same extent as the other organisms (data not shown), indicating that deficiency in the chemiluminescence-triggering ability of the organisms is not due to a lack of ability to contact the $\mathrm{M} \phi$ cell surface. 


\section{DISCUSSION}

Although it is reported that $\mathbf{M} \phi$ s have no myeloperoxidase (Klebanoff, 1980), there is evidence that the halogenation reaction is important for the bactericidal activity of these cells (Lehrer, 1975). There are at least three candidates for the mediator of the $\mathrm{H}_{2} \mathrm{O}_{2}$-dependent halogenation reaction in $\mathrm{M} \phi \mathrm{s}$ : first, myeloperoxidase molecules produced by PMN and taken up by $\mathbf{M} \phi$ s (Hanker \& Giammara, 1983); second, catalase, which exhibits peroxidase activity rather than $\mathrm{H}_{2} \mathrm{O}_{2}$-decomposing activity when $\mathrm{H}_{2} \mathrm{O}_{2}$ is maintained at a very low steady-state concentration, particularly at acid pH (Gee et al., 1970; Klebanoff, 1969; Klebanoff \& Hamon, 1975); third, iron ions in phago(lyso)somes of phagocytic cells which are at a sufficient concentration under physiological conditions to support the halogenation reaction, as described here (about $5 \mu \mathrm{M}$; Flitter et al., 1983; Gutteridge et al., 1981; Halliwell \& Gutteridge, 1984). Also, the $\mathrm{H}_{2} \mathrm{O}_{2}-\mathrm{Fe}$-mediated halogenation reaction is thought to be important for mechanisms related to bacterial killing by phagocytes. When the microbicidal efficacy of the active oxygen-generating system (XOA-Fe-EDTA system), representing direct toxic effects of active oxygen species, is compared with the $\mathrm{H}_{2} \mathrm{O}_{2}-\mathrm{Fe}$-mediated halogenation system, the latter seems to be more important for intracellular killing, particularly of Mycobacterium and Candida.

Because $\mathbf{M} \phi$ s are dominant in the peritoneal cell populations in normal and in BCG-treated mice, the present results reflect essentially the susceptibility of test organisms to resident and activated $\mathrm{M} \phi \mathrm{s}$. S. typhimurium and $M$. tuberculosis, and also $L$. monocytogenes, all of which are intracellular parasites, were highly or markedly resistant to $\mathbf{M} \phi$-mediated killing. In contrast, $C$. albicans, which is highly resistant to the XOA-Fe-EDTA system was rapidly killed by host $\mathrm{M} \phi$ s. Also $C$. albicans was more resistant to the $\mathrm{H}_{2} \mathrm{O}_{2}-\mathrm{Fe}$-mediated halogenation system than were the other microbes. Thus, the mechanisms of intracellular killing of $C$. albicans may involve other factors, such as cationic proteins, unsaturated fatty acids and lysosomal hydrolases (Martinez \& Carroll, 1980; Miller, 1969) rather than oxygen-dependent mechanisms, as proposed by Lehrer (1972, 1975). Our group (Saito et al., 1984) and Kanai \& Kondo (1979) have suggested the importance of unsaturated free fatty acids (arachidonic, oleic, palmitoleic, etc.) in the intraphagolysosomal killing of mycobacteria, which are resistant to active oxygen species (Yamada et al., 1987) and show considerable resistance to $\mathrm{H}_{2} \mathrm{O}_{2}-\mathrm{Fe}$-mediated halogenation (Table 1). A similar proposal was made earlier by Hemsworth \& Kochan (1978).

In the presence of luminol, chemiluminescence originates from ${ }^{\circ} \mathrm{OH}$ and ${ }^{1} \mathrm{O}_{2}$ rather than from $\mathrm{O}_{2}^{-}$and $\mathrm{H}_{2} \mathrm{O}_{2}$ (Babior, 1978; Brummer et al., 1985; Johnston, 1978), and thus we can recognize more complex intracellular events in $\mathrm{M} \phi \mathrm{s}$ after the onset of the respiratory burst by the chemiluminescence assay than by measurement of $\mathrm{O}_{2}^{-}$and $\mathrm{H}_{2} \mathrm{O}_{2}$ generation. In fact, we previously found that in infections due to Mycobacterium intracellulare or L. monocytogenes, the responsiveness of host M $\phi$ s to PMA in the form of the oxidative burst (which correlates well with the extent of $\mathbf{M} \phi$ activation: Nathan \& Root, 1977; Tomioka \& Saito, 1980) was better represented by chemiluminescence than by $\mathrm{H}_{2} \mathrm{O}_{2}$ release (Saito et al., 1986). In addition, $\mathrm{OH}$, which is detectable by the chemiluminescence assay, is very important for the expression of direct microbicidal activity of active oxygen species (Yamada et al., 1987) and also for halogenation reaction system (Klebanoff, 1982b). Therefore, the chemiluminescence assay is a more reliable indicator of the $\mathrm{O}_{2}$-dependent microbicidal function of a given $\mathrm{M} \phi$ cell than the measurement of $\mathrm{O}_{2}^{-}$and $\mathrm{H}_{2} \mathrm{O}_{2}$ generation.

All the intracellular parasites tested here, except $C$. albicans, were less active than the extracellular parasites in triggering a $\mathrm{M} \phi$ oxidative burst. This finding is consistent with the observations by other investigators that virulent species (or strains) of Candida (Sasada \& Johnston, 1980), Salmonella typhi (Kossack et al., 1981; Miller et al., 1972) and M. intracellulare (Gangadharam \& Edwards, 1984) trigger a reduced respiratory burst in $\mathbf{M} \phi$ s and PMNs. In this study, $S$. typhimurium HKB-1 showed a high resistance to $\mathrm{M} \phi$-mediated bacterial killing, although it was highly sensitive to the XOA-Fe-EDTA system (Yamada et al., 1987) and to the $\mathrm{H}_{2} \mathrm{O}_{2}-\mathrm{Fe}$-mediated halogenation system (Table 1). The inability of this microbe to trigger a $\mathrm{M} \phi$ oxidative burst (Fig. 1) may partly explain this enigmatic status. Alternatively, it is possible that this microbe inhibits phagolysosomal fusion of $\mathbf{M} \phi$ s after phagocytosis as in the case of $M$. tuberculosis (Lowrie, 1983). 


\section{REFERENCES}

BABIOR, B. M. (1978). Oxygen-dependent microbial killing by phagocytes. New England Journal of Medicine 298, 659-668.

Brummer, E., Sugar, A. M. \& Stevens, D. A. (1985). Enhanced oxidative burst in immunologically activated but not elicited polymorphonuclear leukocytes correlates with fungicidal activity. Infection and Immunity 49, 396-401.

Flitter, W., Rowley, D. A. \& Halliwell, B. (1983). Superoxide-dependent formation of hydroxyl radicals in the presence of iron salts; what is the physiological iron chelator? FEBS Letters 158, 310 312.

Gangadharam, P. R. J. \& Edwards, C. K., III (1984). Release of superoxide anion from resident and activated mouse peritoneal macrophages infected with Mycobacterium intracellulare. American Review of Respiratory Diseases 130, 834-838.

Gee, J. B. L., Vassallo, C. L., Bell, P., Kaskin, J., BASFORD, R. E. \& Field, J. B. (1970). Catalasedependent peroxidative metabolism in the alveolar macrophage during phagocytosis. Journal of Clinical Investigation 49, 1280-1287.

Gutteridge, J. M. C., Rowley, D. A. \& Halliwell, B. (1981). Superoxide-dependent formation of hydroxyl radicals in the presence of iron salts; detection of 'free' iron in biological systems by using bleomycin-dependent degradation of DNA. Biochemical Journal 99, 263-265.

Halliwell, B. \& Gutteridge, J. M. C. (1984). Oxygen toxicity, oxygen radicals, transition metals and disease. Biochemical Journal 219, 1-14.

Hanker, J. S. \& Giammara, B. L. (1983). Neutrophil pseudoplatelets: their discrimination by myeloperoxidase demonstration. Science 220, 415-417.

Hemsworth, G. R. \& KOCHAN, I. (1978). Secretion of anti-mycobacterial fatty acids by normal and activated macrophages. Infection and Immunity 19, 170177.

JoHnston, R. B., JR (1978). Oxygen metabolism and the microbicidal activity of macrophages. Federation Proceedings 37, 2759-2764.

KANAI, K. \& KONDO, E. (1979). Antibacterial and cytotoxic aspects of long-chain fatty acids as cell surface events: selected topics. Japanese Journal of Medical Science and Biology 32, 135-174.

KLEBANOFF, S. J. (1968). Myeloperoxidase-halidehydrogen peroxide antibacterial system. Journal of Bacteriology 95, 2131-2138.

KLEBANOFF, S. J. (1969). Antimicrobial activity of catalase at acid $\mathrm{pH}$. Proceedings of the Society for Experimental Biology and Medicine 132, 571-574.

KLEBANOFF, S. J. (1974). Role of the superoxide anion in the myeloperoxidase-mediated antimicrobial system. Journal of Biological Chemistry 249, 3724-3728.

KLEBANOFF, S. J. (1980). Oxygen metabolism and the toxic properties of phagocytes. Annals of Internal Medicine 93, 480-489.

Klebanoff, S. J. (1982a). The iron- $\mathrm{H}_{2} \mathrm{O}_{2}$-iodide cytotoxic system. Journal of Experimental Medicine 156, 1262-1267.

KLEBANOFF, S. J. (1982b). Iodination catalyzed by the xanthine oxidase system: Role of hydroxyl radicals. Biochemistry 21, 4110-4116.

Klebanoff, S. J. \& Hamon, C. B. (1975). Antimicro- bial systems of mononuclear phagocytes. In Mononuclear Phagocytes in Immunity. Infection and Pathology, pp. 507-529. Edited by $R$. van Furth. Oxford: Blackwell Scientific Publications.

KlebanofF, S. J. \& ShePard, C. C. (1984). Toxic effect of the peroxidase-hydrogen peroxide-halide antimicrobial system on Mycobacterium leprae. Infection and Immunity 44, 534-536.

Kossack, R. E., Guerrant, R. L., Densen, P., Schadelin, J. \& Mandell, G. L. (1981). Diminished neutrophil oxidative metabolism after phagocytosis of virulent Salmonella typhi. Infection and Immunity 31, 674-678.

LEHRER, R. I. (1972). Functional aspects of a second mechanism of candidacidal activity by human neutrophils. Journal of Clinical Investigation 51, 2566-2572.

LEHRER, R. I. (1975). The fungicidal mechanisms of human monocytes. 1 . Evidence for myeloperoxidaselinked and myeloperoxidase-independent candidacidal mechanisms. Journal of Clinical Investigation 55, 338-346.

Levitz, S. \& Diamond, R. D. (1984). Killing of Aspergillus fumigatus spores and Candida albicans yeast phase by the iron-hydrogen peroxide-iodide cytotoxic system: comparison with the myeloperoxidase-hydrogen peroxide-halide system. Infection and Immunity 43, 1100-1 102.

LOCKSLEY, R. M., JACOBS, R. F., WILSON, C. B., Weaver, W. M. \& KlebanofF, S. J. (1982). Susceptibility of Legionella pneumophila to oxygendependent microbicidal system. Journal of Immunology 129, 2192-2197.

LowRIE, D. B. (1983). How macrophages kill tubercule bacilli. Journal of Medical Microbiology 16, 1-12.

Martinez, R. J. \& Carroll, S. F. (1980). Sequential metabolic expressions of the lethal process in human serum-treated Escherichia coli; role of lysozyme. Infection and Immunity 28, 735-745.

Miller, T. E. (1969). Killing and lysis of Gramnegative bacteria through the synergistic effect of hydrogen peroxide, ascorbic acid, and lysozyme. Journal of Bacteriology 98, 949-955.

Miller, R. M., Garbus, J. \& Hornick, R. B. (1972). Lack of enhanced oxygen consumption by polymorphonuclear leukocytes on phagocytosis of virulent Salmonella typhi. Science 175, 1010-1011.

Nathan, C. F. \& RoOt, R. K. (1977). Hydrogen peroxide release from mouse peritoneal macrophages: dependence on sequential activation and triggering. Journal of Experimental Medicine 146, 1648-1662.

SAIto, H., Tomioka, H. \& Yoneyama, T. (1984). Growth of group IV mycobacteria on medium containing various saturated and unsaturated fatty acids. Antimicrobial Agents and Chemotherapy 26, 164-169.

SaITO, H., TOMIOKA, H., Yamada, Y. \& JidOI, J. (1986). Oxidative and phagocytic functions of macrophages during infections induced in mice by Mycobacterium intracellulare and Listeria monocytogenes. Journal of General Microbiology 132, 1117-1125.

SASADA, M. \& Johnston, R. B., JR (1980). Macrophage microbicidal activity: correlation between phagocytosis-associated oxidative metabolism and the 
killing of Candida by macrophages. Journal of Experimental Medicine 152, 85-98.

TomioKa, H. \& SaITo, H. (1980). Hydrogen peroxidereleasing function of chemically elicited and immunologically activated macrophages: differential response to wheat germ lectin and concanavalin A. Infection and Immunity 29, 469-476.
Yamada, Y., Saito, H., Tomioka, H. \& JidoI, J. (1987). Susceptibility of micro-organisms to active oxygen species: sensitivity to the xanthine-oxidase-mediated antimicrobial system. Journal of General Microbiology 133, 2007-2014. 